\title{
Carabid beetle species as a biological indicator for different habitat types of agricultural landscapes in Korea
}

\author{
Banghun Kang ${ }^{1, *}$, Joon-Ho Lee ${ }^{2}$ and Jong-Kyun Park ${ }^{3}$ \\ ${ }^{1}$ National Academy of Agricultural Science, Rural Development Administration, Suwon 441-707, Korea \\ ${ }^{2}$ Entomology program, Department of Agricultural Biotechnology, Seoul National University, Seoul 151-921, Korea \\ ${ }^{3}$ College of Ecology and Environmental Sciences, Kyungpook National University, Sangju 742-711, Korea
}

\begin{abstract}
In the current study, several carabid beetle species were proposed as potential biological indicators for different habitat types (levee, upland dike, hillock, and streamside) of agricultural landscapes focusing on agrobiont species. Synuchus arcuaticollis and Synuchus orbicollis were found in all habitat types, indicating that they are general species for all habitat types. Harpalus eous and Synuchus cycloderus are potential bioindicator species for the paddy levee and hillock habitats, respectively. Amara pseudosimplicidens, Anisodactylus punctatipennis, and Chlaenius ocreatus, which occurred widely, and Bembidion morawitzi, which occurred only in the streamside habitat, are potential bioindicators for the streamside habitat.
\end{abstract}

Key words: bioindicator, carabid beetle, habitat, rural landscape

\section{INTRODUCTION}

Intensive land use for forestry and agriculture has led to a marked increase in habitat patchiness on various spatial scales in agricultural landscapes. Habitat patches may be isolated "islands" within another habitat type. For example, a forest stand can be confined to a large monocultural agricultural field, or a pasture can be located within a forest. Habitat patchiness affects the spatial distribution of invertebrates at several spatial scales (Niemelä et al. 1992, Niemelä 1997, 1999, Kinnunen and Tiainen 1999).

Biological indicators can be very useful for assessing habitats if they are reasonably representative of the habitat since using only a few species groups, e.g., through extrapolation, is a rapid technique. A useful indicator species has been defined as one that is distributed over a broad geographic area, has specialization in certain habitats, provides early warning of change, is easy and cost- effective to survey, is relatively independent of sample size, has a response that reflects the responses of other species, is easily distinguishable between natural cycles or trends and those induced by anthropogenic stress, and should be of potential economic importance (e.g., Noss 1990, Pearson and Cassola 1992, Niemelä 2000, Samways 2006). However, it is difficult to find species or species groups that have all of the characteristics mentioned above (Noss 1990, Pearson and Cassola 1992). Carabid beetles are widely recognized as potentially valuable indicators of environmental variation since they are diverse, can be easily sampled, and are sensitive to changes in the physical and biological environment (Lövei and Sunderland 1996, Rainio and Niemelä 2003).

Kang et al. (2009) reported that the composition of carabid beetle fauna, dominant species, and carabid beetle

\section{Open Access http://dx.doi.org/10.5141/JEFB.2012.006}

This is an Open Access article distributed under the terms of the Creative Commons Attribution Non-Commercial License (http://creativecommons. org/licenses/by-nc/3.0/) which permits unrestricted non-commercial use distribution, and reproduction in any medium, provided the original work is properly cited. pISSN: 1975-020X eISSN: 2093-4521
*Corresponding Author
E-mail: ipmkbh@korea.kr Tel: $+82-31-290-0281$ 
assemblage patterns differed among habitats (levee, dike, hillock, streamside) in the same sites of the current study.

In this study, we aimed to propose some potential indicator species for representing these habitat types from the generalist and specialist aspects for different habitat types in agricultural landscapes and to investigate their suitability as indicators by analyzing their correlation with the spider group.

\section{MATERIALS AND METHODS}

Carabid beetle samplings were conducted using unbaited pitfall traps in four adjacent habitat types (levee, upland dike, hillock, streamside) in three sites, Paltanmyeon, Hwaseng-si, and Gyeonggi-do, in two-week intervals from November 2000 to November 2002. Detailed information about the study site characteristics and samplings were published previously (Jung et al. 2008, Kang et al. 2009). The nomenclature and identification of carabid beetle species have also been published elsewhere (Kang et al. 2009).

Analyses were conducted of the carabid species diversity, and a cluster analysis was conducted using the dominant species. An agrobiont species is defined as a dominant species in various habitats of the farm village area (Samu and Szinetar 2002). Twenty-two agrobiont species represented $>3 \%$ of the total numbers in at least one habitat type. This list was published previously (Kang et al. 2009). The agrobiont carabid species diversity was compared among the habitat types using Shannon's diversity index (Pielou 1975). To compare the incidence of opportunistic species, the carabid dominance structure was investigated by construction of an agrobiont species rank-abundance plot and an agrobiont abundance distribution model (Niemelä et al. 2002) at four habitat types using Species Diversity and Richness III (Pisces Conservation 2004). Agrobionts are considered ubiquitous species that occur in a wide range of habitats and are considered typical pioneer species with a well developed dispersal capacity, especially in arable land (Samu and Szinetar 2002, Lambeets et al. 2008).

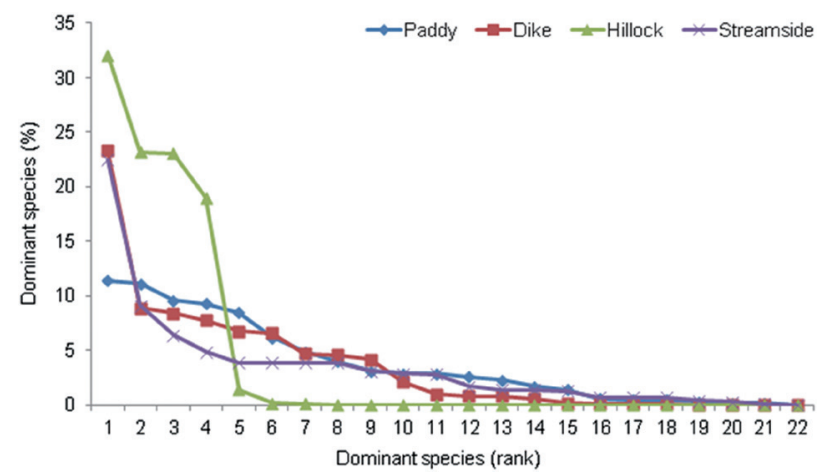

Fig. 1. The dominance structure of the 22 agrobiont species in carabid beetle communities in the four habitat types.

We used the agrobiont species to select the indicator species and investigate the body size and wing types of the selected species as potential bioindicators to understand their ecological traits across landscape elements (Fournier and Loreau 2001, Niemelä et al. 2002).

The relationship was analyzed between the carabid beetle and spider groups, both of which were collected in the same investigation sites to determine whether carabid beetles can be utilized as bioindicators. Spider group data from the Korea Science and Engineering Foundation report were used (Lee 2003).

\section{RESULTS AND DISCUSSION}

The Shannon's diversity index values for the 22 agrobiont carabid beetle species were 1.452-2.630 among the four different habitat types (Table 1). The diversity was lower in the hillock habitat than in any other habitat type. With regard to diversity index, the value of Simpson's Evenness was lower in the hillock habitat than in any other habitat types (Table 1).

The dominance structure of the 22 agrobiont species in the carabid beetle communities of the four habitat types is illustrated using rank-abundance curves (Fig. 1). The dominance structure differed among habitat types. The structure of abundance distribution in the levee habitat

Table 1. Shannon's diversity and evenness index values among the four habitat types using 22 agrobiont carabid beetle species

\begin{tabular}{lcccc}
\hline & Paddy & Dike & Hillock & Streamside \\
\hline Shannon's diversity index & $2.630 \pm 0.0009$ & $2.265 \pm 0.0007$ & $1.452 \pm 9.4^{\mathrm{E}-5}$ & $2.483 \pm 0.0017$ \\
Evenness index & 0.8509 & 0.7327 & 0.4697 & 0.8032 \\
\hline
\end{tabular}

Analyses were made using Species Diversity \& Richness III (Pisces Conservation 2004). 
highly fit a broken stick model $(P=0.934)$, while those in the dike, hillock, and streamside habitats highly fit a truncated $\log$ normal distribution $(P=0.894,0.246$, and 0.862 , respectively) (Table 2).

Synuchus arcuaticollis and Synuchus orbicollis dominated all habitat types. Some species were highly dominant in one specific habitat type versus the other habitat types. Harpalus eous was highly dominant $(>37 \times)$ in the paddy levee compared to the other habitat types. Harpalus tridens was highly dominant $(>6 \times)$ in the upland dike compared to the other habitat types. Synuchus cycloderus was highly dominant $(>23.1 \times)$ in the hillock compared to the other habitat types. Several agrobiont species were highly dominant in the streamside compared to the other habitat types, including Bembidion morawitzi, which was found only in the streamside; Amara pseudosimplicidens $(>19.5 \times)$; Anisodactylus punctatipennis (>10.7x); and Chlaenius ocreatus (>13 $\times$ ).

S. arcuaticollis and S. orbicollis occurred highly in all habitat types, indicating that they are general species in all habitat types. H. eous, S. cycloderus, A. pseudosimplicidens, A. punctatipennis, and Chlaenius ocreatus appeared to be specialized species for specific habitat types, indi- cating that they are potential bioindicators. B. morawitzi occurred only in the streamside area, indicating that it is a highly specialized species that can be a bioindicator for the streamside habitat. H. tridens occurred significantly more in the upland dike, but it was less representative of a specific habitat type than the above potential bioindicator species. General habitat carabid beetle types such as $S$. arcuaticollis and S. orbicollis can likely be used to evaluate the environment by their occurrence share in each habitat, while the special habitat beetle types can be used to evaluate the environment according to their existence or nonexistence.

The body size of the selected species for potential bioindicators was classified into three groups: small $(<10 \mathrm{~mm})$, medium $(10-20 \mathrm{~mm})$, and large $(>20 \mathrm{~mm})$, which can be used to examine the relationship between ecological traits and the response to disturbances for species across landscape elements (Niemelä et al. 2002). The wing types of the selected species bioindicators were classified into macropterous (hindwing fully developed) according to the degree of hindwing development (Table 3), which was calculated for each species as the ratio between the wing area and the elytron area (Fournier and Loreau 2001).

Table 2. Analysis of abundance distribution of the four habitat types at three sites

\begin{tabular}{lcccc}
\hline & \multicolumn{4}{c}{ Abundance distribution } \\
\cline { 2 - 5 } Habitat & Geometric & Log series & $\begin{array}{c}\text { Truncated } \\
\text { log normal }\end{array}$ & Broken stick \\
\hline Paddy & $\times$ & $\circ(P=0.058)$ & $\circ(P=0.666)$ & $\circ(P=0.934)$ \\
Dike & $\times$ & $\circ(P=0.295)$ & $\circ(P=0.898)$ & $\circ(P=0.134)$ \\
Hillock & $\times$ & $\circ(P=0.090)$ & $\circ(P=0.246)$ & $\times$ \\
Streamside & $\times$ & $\times$ & $\circ(P=0.862)$ & $\circ(P=0.840)$ \\
\hline
\end{tabular}

"Analyses were made using Species Diversity \& Richness III (Pisces Conservation 2004).

Table 3. Body sizes and wing types of the proposed bioindicator species in four habitat types

\begin{tabular}{|c|c|c|c|c|c|}
\hline \multirow{2}{*}{ Species name } & \multirow{2}{*}{$\begin{array}{l}\text { Body size } \\
\text { (mm) }\end{array}$} & \multicolumn{4}{|c|}{ Wing type } \\
\hline & & Hindwing & Elytra & $\%$ & Type* \\
\hline Synuchus arcuaticollis & 9.3 & 8.0 & 6.1 & 131 & M \\
\hline Synuchus orbicollis & 10.0 & 8.3 & 6.0 & 138 & M \\
\hline Harpalus eous & 13.8 & 11.8 & 7.5 & 157 & M \\
\hline Synuchus cycloderus & 12.3 & 10.2 & 7.6 & 134 & M \\
\hline Amara pseudosimplicidens & 9.0 & 7.7 & 5.5 & 140 & M \\
\hline Anisodactylus punctatipennis & 11.5 & 8.9 & 6.3 & 141 & M \\
\hline Chlaenius ocreatus & 14.3 & 13.0 & 8.5 & 153 & M \\
\hline Bembidion morawitzi & 4.5 & 4.2 & 2.7 & 156 & M \\
\hline
\end{tabular}

"M (macropterous): hindwing fully developed. 
Carabid communities may sensitively respond to wide environmental elements such as habitat structure, habitat type, and topographic distance (Weaver 1995, Dufrêne and Legendre 1997). Even if a habitat environment remains the same, the qualitative composition of the carabid beetle may differ in response to the strength of neighboring habitat factors or according to the direction of a disturbance (Rainio and Niemelä 2003). The above mentioned species appear to have high potential as biological indicator species to abstract specific habitat types. Differences in habitat types and environment affect species composition and abundance.

The relationship between the carabid beetle group and the spider group collected at the same investigation sites was analyzed (Table 4). The correlation of species number between the carabid beetle and spider groups was modest $(r, 0.35$ to 0.48$)$ in three habitat types but was low in the hillock habitat. Jung et al. (2008) showed that all four habitat types were well separated by ground-dwelling spider species composition. The modest correlation between species numbers of carabid beetles and ground-dwelling spiders indicates that the distribution characteristics of the carabid beetle and ground-dwelling spiders may be similar.

Some studies have reported correlations between species richness of different species groups, e.g., tiger beetles and birds (Pearson and Cassola 1992), butterflies and flowering plants (Kremen 1992), and several insect groups and overall species diversity (Wise 1993, Duelli and Obrist 1998). However, several other studies reported no or very low correlations between species richness of different taxonomic groups (plants, mosses, birds, butterflies, beetles, etc.) (Kremen 1992, Prendergast et al. 1993, Oliver and Beattie 1996, Lawton et al. 1998, Jonsson and Jonsell 1999). There are currently no clear answers regarding whether there are significant correlations between taxonomic groups, but the ecological requirements of the species and the observation scale can provide some guidance. There may be no correlation between species groups with different ecological requirements (Lawton et al. 1998, Jonsson and Jonsell 1999), whereas a correlation can be expected between species that depend on the same ecological factors (e.g., moisture, soil quality, and

Table 4. Correlation coefficient between carabid beetle and spider groups by habitat type

\begin{tabular}{ccccc}
\hline & Paddy & Dike & Hillock & Streamside \\
\hline No. of Species & $0.351^{\mathrm{b}}$ & $0.349^{\mathrm{b}}$ & 0.171 & $0.484^{\mathrm{a}}$ \\
\hline
\end{tabular}

"Statistically significant correlation ( $\left.{ }^{\mathrm{a}} P<0.01 ;{ }^{\mathrm{b}} P<0.15\right)$. dead wood). Species richness also depends on the observation scale (e.g., Blake et al. 1994, Weaver 1995). Further studies should be conducted to elucidate whether one type of taxonomic group can be used as a surrogate for assessing biodiversity of different habitat types.

\section{ACKNOWLEDGMENTS}

This work was supported by the Korean Science and Engineering Foundation (KOSEF) (R01-2000-000-002000 ), and the Research Program for Agricultural Science and Technology Development, National Academy of Agricultural Science, Rural Development Administration, Republic of Korea.

\section{LITERATURE CITED}

Blake S, Foster GN, Eyre MD, Luff ML. 1994. Effects of habitat type and grassland management practices on the body size distribution of carabid beetles. Pedobiologia 38: 502-512.

Duelli P, Obrist MK. 1998. In search of the best correlates for local organismal biodiversity in cultivated areas. Biodivers Conserv 7: 297-309.

Dufrêne M, Legendre P. 1997. Species assemblages and indicator species: the need for a flexible asymmetrical approach. Ecol Monogr 67: 345-366.

Fournier E, Loreau M. 2001. Respective roles of recent hedges and forest patch remnants in the maintenance of ground-beetle (Coleoptera: Carabidae) diversity in an agricultural landscape. Landsc Ecol 16: 17-32.

Jonsson BG, Jonsell M. 1999. Exploring potential biodiversity indicators in boreal forests. Biodivers Conserv 8: 14171433.

Jung MP, Kim ST, Kim H, Lee JH. 2008. Biodiversity and community structure of ground-dwelling spiders in four different field margin types of agricultural landscapes in Korea. Appl Soil Ecol 38: 185-195.

Kang BH, Lee JH, Park JK. 2009. The study on the characteristics of ground beetle (Coleoptera: Carabidae) Community for conservation of biodiversity in agricultural landscape. Korean J Environ Ecol 23: 545-552.

Kinnunen H, Tiainen J. 1999. Carabid distribution in a farmland mosaic: the effect of patch type and location. Ann Zool Fenn 36: 149-158.

Kremen C. 1992. Assessing the indicator properties of species assemblages for natural areas monitoring. Ecol Appl 2: 203-217. 
Lambeets K, Hendrickx F, Vanacker S, Van Looy K, Maelfait JP, Bonte D. 2008. Assemblage structure and conservation value of spiders and carabid beetles from restored lowland river banks. Biodivers Conserv 17: 3133-3148.

Lawton MD, Dales RE, White J. 1998. The influence of house characteristics in a Canadian community on microbiological contamination. Indoor Air 8: 2-11.

Lee JH. 2003. GIS Modeling and Monitoring of Agricultural and Aquatic Ecosystem Using Biological Indicators at a Watershed Scale. Korea Science and Engineering Foundation, Daejeon.

Lövei GL, Sunderland KD. 1996. Ecology and behavior of ground beetles (Coleoptera: Carabidae). Annu Rev Entomol 41: 231-256.

Niemelä J. 1997. Invertebrates and boreal forest management. Conserv Biol 11: 601-610.

Niemelä J. 1999. Ecology and urban planning. Biodivers Conserv 8: 119-131.

Niemelä J. 2000. Biodiversity monitoring for decision-making. Ann Zool Fenn 37: 307-317.

Niemelä J, Haila Y, Halme E, Pajunen T, Punttila P. 1992. Small-scale heterogeneity in the spatial distribution of carabid beetles in the southern Finnish taiga. J Biogeogr 19: 173-181.

Niemelä J, Kotze DJ, Venn S, Penev L, Stoyanov I, Spence J, Hartley D, de Oca EM. 2002. Carabid beetle assemblages (Coleoptera, Carabidae) across urban-rural gradients: an international comparison. Landsc Ecol 17: 387-401.
Noss RF. 1990. Indicators for monitoring biodiversity: a hierarchical approach. Conserv Biol 4: 355-364.

Oliver I, Beattie AJ. 1996. Designing a cost-effective invertebrate survey: a test of methods for rapid assessment of biodiversity. Ecol Appl 6: 594-607.

Pearson DL, Cassola F. 1992. World-wide species richness patterns of tiger beetles (Coleoptera: Cicindelidae): indicator taxon for biodiversity and conservation studies. Conserv Biol 6: 376-391.

Pielou EC. 1975. Ecological Diversity. John Wiley and Sons, New York.

Pisces Conservation. 2004. Species Diversity and Richness III (Software Program). Pisces Conservation, New Milton.

Prendergast JR, Quinn RM, Lawton JH, Eversham BC, Gibbons DW. 1993. Rare species, the coincidence of diversity hotspots and conservation strategies. Nature 365: 335-337.

Rainio J, Niemelä J. 2003. Ground beetles (Coleoptera: Carabidae) as bioindicators. Biodivers Conserv 12: 487-506.

Samu F, Szinetar C. 2002. On the nature of agribiont spiders. J Arachnol 30: 389-402.

Samways MJ. 2006. Insect extinctions and insect survival. Conserv Biol 20: 245-246.

Weaver JC. 1995. Indicator species and scale of observation. Conserv Biol 9: 939-942.

Wise DH. 1993. Spiders in Ecological Webs. Cambridge University Press, Cambridge. 